Abstracta Iranica Iranica

Revue bibliographique pour le domaine irano-aryen

Volume 32-33 | 2013

Comptes rendus des publications de 2009-2010

\title{
Antonio Panaino. Sasanian Astronomy and Astrology in the Contribution of David Pingree
}

\section{Živa Vesel}

\section{(2) OpenEdition}

1 Journals

\section{Édition électronique}

URL : http://journals.openedition.org/abstractairanica/40714

DOI : 10.4000/abstractairanica.40714

ISSN : 1961-960X

Éditeur :

CNRS (UMR 7528 Mondes iraniens et indiens), Éditions de l'IFRI

\section{Édition imprimée}

Date de publication : 1 décembre 2013

ISSN : 0240-8910

\section{Référence électronique}

Živa Vesel, «Antonio Panaino. Sasanian Astronomy and Astrology in the Contribution of David Pingree ", Abstracta Iranica [En ligne], Volume 32-33 | 2013, document 399, mis en ligne le 01 juillet 2016, consulté le 27 septembre 2020. URL : http://journals.openedition.org/abstractairanica/40714 ; DOI : https://doi.org/10.4000/abstractairanica.40714

Ce document a été généré automatiquement le 27 septembre 2020

Tous droits réservés 


\title{
Antonio Panaino. Sasanian Astronomy and Astrology in the Contribution of David Pingree
}

\author{
Živa Vesel
}

\section{RÉFÉRENCE}

Antonio Panaino. «Sasanian Astronomy and Astrology in the Contribution of David Pingree », in : G. Gnoli \& A. Panaino, eds., Kayd. Studies in the History of Mathematics, Astronomy and Astrology in Memory of David Pingree. Rome, IsIAO, 2009, p. 73-103.

Dans le domaine de l'astronomie et l'astrologie, l'Iran pré-islamique, notamment sassanide, a intégré et retravaillé diverses doctrines étrangères et les a transmises au monde islamique et à l'Occident. Cet apport de l'Iran à l'histoire du savoir n'aurait pas été perçu à sa juste valeur sans la contribution des travaux du regretté David Pingree. Connaisseur de sources grecques, babyloniennes, et en particulier indiennes, ses analyses ont été décisives pour déterminer une série de sujets relatifs à l'époque sassanide, dont: - les trois rédactions successives de tables astronomiques; - les influences indiennes dans l'astrologie (horoscopes avec planètes en exaltation; La Queue et la Tête du 'Dragon'; techniques interrogatives ; mansions lunaires, etc.) ;l'importance de la théorie des conjonctions de Saturne et de Jupiter [à ce propos, voir dans ce même volume les articles de C. Burnett et S. De Meis, ainsi que celui de S. Buscherini, "Considerations on the Origins of the Sasanian Saturn-Jupiter Conjunctions Theory », p. 31-38], menant à l'établissement de l'astrologie historique, très populaire dans le monde islamique ; - l'évaluation des trois séries de décans, avec précisions importantes sur la série indienne; - les traductions du grec et du sanskrit datant de l'époque sassanide, préservées en arabe. 
2 Les travaux de D. Pingree, uniques par l'envergure de l'érudition, permettent par ailleurs de tracer les influences de l'Iran pré-islamique, jusqu'aux textes latins d'une part, byzantins de l'autre.

\section{AUTEURS}

\section{ŽIVA VESEL}

CNRS, Mondes iranien et indien, Paris 